The specimen figured is the first Pteraspidian fossil ever detected in the numerous erratic Silurian boulders of Northern Germany, and is not selected from among a great number of similar fossils.

The two shields are not brought into contact accidentally, but correspond to each other most clearly in their size and in their mutual position.

The other fragments of similar structure occurring in the same piece of stone, probably represent the cornua and some of the scales.

St. Petersbub:

${ }_{16}^{16} / 27$ May, 1873.

M.G. F. Sommidt.

NOTE ON HOLASPIS SERTCEUS.

Srr,-Will you kindly insert the inclosed outline sketch of a lateral view of the shield of Holaspis, which exhibits the orbital notch in a way which was impossible in the view of the upper

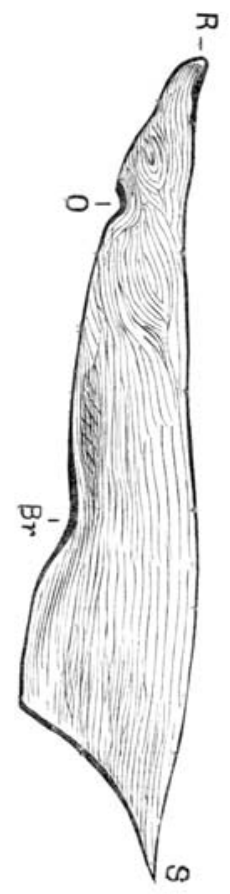

Outline lateral view of the shield of Holaspis sericeus. $R$. Rostrum. S. Spine. O. Orbital notch. $B r$. Depression corresponding to the cornual perforation or branchial aperture of Pterapis. 
surface published in your last Number. Let me add that the striations, though rightly rendered as to direction in that lithograph, are not given with sufficient fineness or regularity. I may refer your readers to the plates of Scaphaspis Lloydii and the restorations of the shield of Pteraspis in my monograph for accurate reproduction. of striations having the same character as those of Holaspis. It is especially with Seaphaspis that Holaspis agrees in the form and size of its skin-like grooving.

E. RAY ILAKKESTHE.

OxFORD, June 18th.

\section{GEOLOGICAL PROBLEMS.}

SrR,-The following methods of finding by diagram, in place of calculation, certain data for the construction of correct geological sections, may be found useful.

Problem 1.-To find the apparent angle in any required section from the full dip, and the deviation of its direction from that of the section.

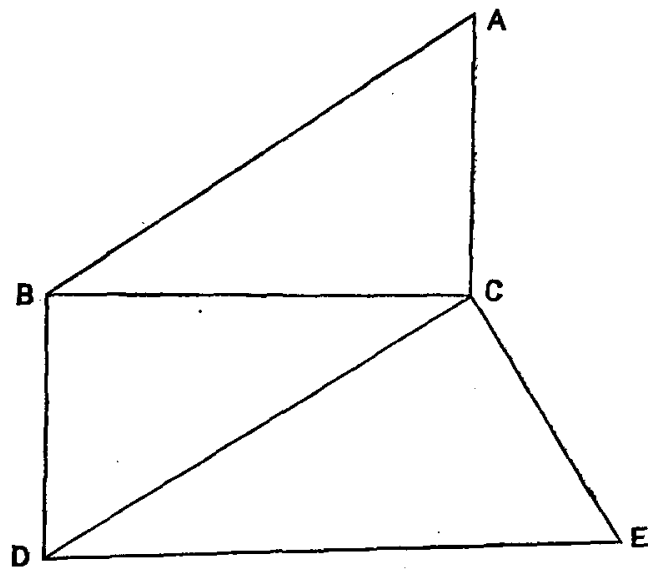

Constract the right-angled triangle $A B C$, with $A B C$ equal to the full dip; also the right-angled triangle $B C D$, with $B C D$ equal to the deviation; lastly the right-angled triangle $C D E$, in which $C E$ is equal to $A C$.

Then $C D E$ is the required apparent angle.

Proof--If $A B C$ be a vertical plane along the full dip, and $C D E$ the vertical plane of section. $B C D$ will be a horizontal plane, and $A C, C E$ will coincide, so that $B D, A E$ will be the plane of stratifcation, giving the apparent angle $C D E$ along the section.

Problem 2.-From two apparent dips ${ }^{1}$ to find the full dip and its direction.

1 Any three points, not being in a straight line, on a line of out-crop, will furnish 